\title{
A thematic analysis of the medical practitioners' reaction towards patients' explanation in notifying their health condition in Malaysia3
}

\author{
Wan Yusoff Wan Shaharuddin ${ }^{1, a^{*}}$, Mariah Muda ${ }^{2, b}$ and Soo-Yin See ${ }^{1, c}$ \\ ${ }^{1}$ Centre for Language Studies and Generic Development, Universiti Malaysia Kelantan, Kelantan, \\ Malaysia \\ ${ }^{2}$ Faculty of Communication and Media Studies, Universiti Teknologi MARA, Selangor, Malaysia \\ E-mail address: yusoff.ws@umk.edu.my; ${ }^{b}$ mariahmuda62@yahoo.com; 'see@umk.edu.my
}

Keywords: Interpersonal communication; psychiatric patients; medical practitioners

\begin{abstract}
Effective interpersonal communication between patients and the medical practitioners has always been the medium for information exchange between both parties. This qualitative research is conducted to determine how the medical practitioners react to the patients' complaints in any given medical interaction settings. The data for the entire research were obtained through indepth interviews, conducted with six informants. The purposive sampling method was utilized to determine the appropriate informants to be chosen with the traits of a psychiatric patient diagnosed with any psychiatric complication. The data were analysed by deriving themes from the in-depth interviews using thematic analysis method. The data acquired from the informants have contributed to a few themes which have indicated the medical practitioners' reaction to the patients' complaints. Based on the findings, the researcher has concluded that the medical practitioners involved in treating the informants were not responsive enough to the patients' complaint.
\end{abstract}

\section{INTRODUCTION}

In a medical transaction between a patient and a medical practitioner, interpersonal communication will come in hand in order to help to the medical practitioner to pre-diagnose the patient and identify the applicable medical solution. Harter et al [11] describe interpersonal communication as the process of generating meaning through messages which occurs between two speakers whereby the situation is also allowing both people to have mutual opportunities in speaking and also listening. Before diagnosing the patient with any disease or health problems, the medical practitioners need to be provided with proper description in order to help them to determine any applicable treatment for the patients. In order to achieve this goal, medical transaction between speakers, the patient and the medical practitioners, need to be precise, henceforth preventing any mistakes that can cause medical fatality to the patient. Effective communication between patient and the medical practitioners has always been the medium for informative exchange between both parties. As mentioned by Domingo [3], patient's satisfaction with the medical encounter is the standard used to measure the effectiveness of doctor-patient communication. Furthermore, the patient will also be attached to a treatment provided if the medical practitioner manages to show that he is concern about the well-being of the patient and is committed to help the patient to recover [10]. Nevertheless, patient who is being attended by the medical practitioners are still facing a few major barriers in conveying the message of pain and instability of their health. Medical practitioners such as doctor, nurse, pharmacist and medical attendant are also having a hard time in diagnosing patient's health problem and determining the proper treatment or medicine to be consumed. However, miscommunication can occur if both patient and medical practitioners interpreted their conversation in a different context. Despite extensive acknowledgement of the importance of interpersonal communication, the subject is still being denied from contributing to the medical training [3]. Thus, this qualitative research is conducted to determine how the medical practitioners react to the patients' complaint in any given medical interaction settings. 


\section{METHODOLOGY}

\subsection{The study setting and the subjects}

The setting of the study and the informants' selection are important in order to achieve maximum sufficiency in the data collection process. The research approach formulated for this study is focusing on determining the medical practitioners' reactions towards the patients' complaints in any given medical interaction. The informants chosen in this study were psychiatric patients who have had the experience of involving themselves in medical interactions with any medical practitioners in the medical institutions listed by the Malaysian Mental Health Association (MMHA) which are located in the Klang Valley, Selangor, Malaysia. Other than that, the researcher also went to the headquarter of the MMHA in Jalan Othman, Petaling Jaya, Selangor, Malaysia in order to select the psychiatric patients that can contribute towards the research. The interview sessions were conducted between the researcher and the psychiatric patients recommended by MMHA. The exact number of respondents involved will be solely depending on the questions asked, the data being gathered, the progressing analysis and the resources that the researcher has [14].

\subsection{Data gathering and analysis}

The study has utilized in-depth interview as one of the main methods in the data collection process of a qualitative research. Two voice-recording devices were used and the researcher himself will write down key points in order to establish efficiency in the data gathering process. The data analysed is based on the participants or informants and the investigator's first-hand experience [14]. Before the data gathering process started, the informants were asked to fill up a consent letter in order to ensure that they have voluntarily participated in the research. The informants were then briefed about the main objectives of the research.

In the process of analysing the data, the thematic analysis method was utilized in order to further elicit the information derived from the in-depth interviews. According to Braun and Clarke [15], thematic analysis can be defined as a qualitative analytic method for identifying, analysing and reporting themes or patterns within a set of data. Themes derived will help to capture important essence about the data which is related to the research questions and represents some level of patterned response or meaning within the data set [15]. Braun and Clarke [15] also listed six phases in performing the thematic analysis which are becoming familiar with the data, generating initial codes, searching for themes, reviewing themes, defining and naming themes and producing the report. In order to get a further understanding of the data that the researcher have collected, it is important for the researcher to be involved deeply in the data to the extent that the researcher are familiar with the depth and breadth of the content. Braun and Clarke [15] mentioned that the researcher needs to immerse himself in the content by reading the data repeatedly and also reading the data in an active way. Through the reading process, the researcher will be assisted in the process of looking for meanings, patterns and also the idea of the content of the data. Braun and Clarke [15] also recommend taking notes and marking ideas before the formal coding process begun. Verbal data such as interviews and speeches need to be transcribed into the written form in order to perform the thematic analysis. According to Riessman [5], although the process of transcribing the data might be frustrating, time consuming and also sometimes boring, it is one of the excellent ways in the process of familiarising the researcher with the data. Other than reading, familiarisation of data can also be done by listening to the audio recorded data and comparing the data with the one that has been orthographically transcribed. This can help to increase the accuracy of the data and also helps the researcher to familiarize with the content. Thus, the researcher followed the step of becoming familiar with the data by firstly transcribing the data from the audio recording device. The researcher listened to the audio recording device while writing out the in-depth interview on a piece of paper. The process was repeated twice in order to reach a point of accuracy in between the audio recording and the transcribed data. The researcher then moved from transcribing the data to reading it in order to have an in-depth understanding of what the informants are saying. Potential themes or related quotations were marked using a pencil in order to leave space for further 
correction to be done when the actual or formal coding process was performed. The process of familiarizing the researcher with the data was repeated all over again to the other data involving six different informants.

The second phase which is known as the phase of generating initial codes began when the researcher have read and familiarised himself with the data, and have generated an initial list of ideas about what is in the data and what is interesting about them [15]. According to Boyatzis [13] codes can be referred as a feature of the data that appears interesting to the researcher, and refer to "the most basic segment, or element, of the raw data or information that can be assessed in a meaningful way regarding the phenomenon." The researcher began the phase of generating initial codes by reading the data that was transcribed earlier. The researcher then manually highlighted the codes in the transcribed data. The researcher used the highlighter to mark the quotations in the indepth interviews that were considered as codes. Other than that, the researcher also wrote down some notes at the highlighted quotations in order to indicate the quotation is relevant to represent the codes. The researcher highlighted as many codes as possible in order to prevent any information from slipping out of the researcher's sight. In order to increase accuracy, the same process was conducted twice with every set of data.

Phase three which is known as the phase of searching for themes began when the researcher had identified a long list of codes derived from the data transcription of the in-depth interviews. Braun and Clarke [15] mentioned that the phase of searching for themes involve the process of refocusing the analysis at the broader level of themes, rather than codes, involves sorting the different codes into potential themes, and collating all the relevant coded data extracts within the identified themes. Visual aids such as mind maps or tables are useful in helping the researcher to analyse and sorting out the codes into different themes. In this phase, the researcher had come out with tables indicating the informant and the codes. The researcher began sorting the codes by searching for any similarities. The similar codes were then put under the same potential themes which are not yet being finalized. Other than that, irrelevant codes were also discarded from the table in order to further clarify the set of data.

The phase of reviewing themes began when the researcher has revised the set of candidate themes. This phase involved the process of refining the candidate themes. According to Braun and Clarke [15], during this phase, the researcher will find out that some candidate themes that were listed in the previous phase were not really themes. Other than that, the researcher will also find out that some of the candidate themes are actually from the same category and some might also be divided to form another new theme [15]. During this phase, the researcher had gone further by analysing the candidate themes and putting them into sub-themes. Other than that, the researcher also merged a few sub-themes that were significant to each other.

Phase five occur when the researcher defined and further refined the themes that will be presented in the data analysis. According to Braun and Clarke [15], define and refine can be referred as identifying the essence of what each theme is about and determining what aspect of the data each theme captures. In this phase, the researcher had gone further by coming out with the actual themes that will be presented in the data analysis.

The final phase of the process involves the production of the report. Phase six began when the researcher has a set of fully worked-out themes, and involves the final analysis and write-up of the report [15]. According to Braun and Clarke [15], the task of the thematic analysis report is to tell the complicated story of the data in order to convince the reader of the merit and validity of the analysis. Therefore, during this phase, the researcher has come out with an in-depth report that is presented in findings and discussions. The researcher had also come out with a table consisting of the themes derived from the data set. The researcher then explained the nature of each theme along with the excerpt that represents the theme that was derived.

In order to reach a point of data saturation, the researcher had transcribed the interviews and also analysed the data from one informant to another. Therefore, when an interview with one informant was finished, the researcher had transcribed the data and analysed them for new themes that emerged. This process was repeated from one informant to another until it reached informant 
six whereby there were no longer new themes derived from the in-depth interviews with informant six. When such event occurred, it has already signified the point of saturation in the data collection process.

\section{FINDINGS AND DISCUSSIONS}

\subsection{An approach to understand medical practitioners' reactions towards patients' explanation in notifying their health condition: The development of themes}

The aim of the research is to discover and understand the medical practitioners' reactions towards patients' explanation in notifying their health condition during the medical consultation involving psychiatric patients and the medical practitioners attending them. In order to ensure the clarity of the information gathered, the themes derived from the in-depth interviews were formed according to the perspective of the psychiatric patients involved in the research. The findings of the research were then presented in accordance to the research question in order to ensure that the themes are aligned with the issue of interpersonal communication problems which occurred in the medical interactions.

\subsection{Medical practitioners' reaction towards patients' explanation in notifying their health condition}

There are twenty-two themes derived from the interview sessions conducted with six informants. Table 1 represents the themes that were derived from in-depth interviews:

Table 1. Medical practitioners' reaction towards patients' explanation in notifying their health condition

\begin{tabular}{|c|l|}
\hline Informants & \multicolumn{1}{|c|}{ Themes } \\
\hline 1 & $\begin{array}{l}\text { Minimum reply, delay, give out instruction and medication, changing } \\
\text { medications, doctor's confusion, asking questions, provide materials to read }\end{array}$ \\
\hline 2 & $\begin{array}{l}\text { Background check, show little understanding, changing doctors, asking } \\
\text { questions, inconsistent explanation }\end{array}$ \\
\hline 3 & $\begin{array}{l}\text { Give out instruction and medication, doctor's confusion, insensitive attitude, } \\
\text { short session, no further explanation }\end{array}$ \\
\hline 4 & $\begin{array}{l}\text { Not aware of patient's condition, take blood samples and perform x-ray, give } \\
\text { out instruction and medication, no further explanation, asking patient's } \\
\text { condition, writing in a file, refuse to listen to patient's opinion, nonverbal } \\
\text { expression }\end{array}$ \\
\hline 5 & $\begin{array}{l}\text { Checking on patient, give out instruction and medication, minimum reply, ask } \\
\text { to come for regular check-up }\end{array}$ \\
\hline 6 & $\begin{array}{l}\text { Background check, ask to come for regular check-up, give out instruction and } \\
\text { medication, no further explanation, asking questions }\end{array}$ \\
\hline
\end{tabular}

\section{i) Minimum reply}

In the process of medical interaction, the 'talk' that occurs usually contains the process of diagnosing the patient, revealing the patient's fear towards the illness, visceral communication, doctors making assumptions of the illness and also the nonverbal reactions experienced by both parties [2]. However, such 'talk' will be ineffective if the doctor was minimizing his reply in the medical transaction involving the face to face interaction with the patients' that they are attending. The excerpts taken from the in-depth interviews of Informant 1 and Informant 5 further explain the situation:

"At that time, I was actually telling all the stuff I know, and they actually say (said) that I'm saying words not in order. I just tell whatever I wanted. Like its one way interaction. I tell them stuff but they reply a little bit." (Informant 1) 
"I do not know why the doctor hasn't said anything. He just gives me some depression medicine, and asks me to relax a bit (to relax)." (Informant 5)

\section{ii) Delay}

The second theme derived from the research question of medical practitioners' reaction to the patients' complaint is the theme of 'delay.' According to Informant 1, the medical practitioner that was attending him took about one week to diagnose him with schizophrenia. The delay in determining the illness occurred due to the doctor's confusion in understanding the nature of Informants' strange way of delivering his complaint regarding to his health condition. The excerpt below explained the medical interaction experienced by Informant 1:

"I don't think they get my illness until very late, (until it is at a very late stage) like after one week they are only sure about it, my illness... because my symptoms are not very critical. Like some (others), they can hear voices, but I do not hear voices. And so until very late only they told me schizophrenia (until then, it was very late that they informed me that I have schizophrenia)." (Informant 1)

\section{iii) Give out instruction and medication}

The theme of 'giving out instruction and medication' was derived in order to indicate the reactions of the medical practitioners after they were informed by the patients' health condition. It is a norm for a doctor to provide instructions as well as the right medical prescription during the interaction or discussion that occurred in the examination room. The excerpts below explain the situation involving Informant 3, 4, 5 and 6:

"Yeah, first the doctor just asked me to rest well and just follows the instructions of the nurses.” (Informant 1)

"His speech indicated that he did not fully understand my situation. However, he just asked me to take the medication that will help to make me feel happy. That was not the answer I was looking for.” (Informant 3)

"When I tell them about my problems, they write down their medical prescription on a medical sheet and give it to me and asked me to get the medicine from the pharmacy the same hospital (in the same hospital) and that's it." (Informant 4)

"I just go and see the doctor. Doctor was just look (looking) at me. Check with me (examining me). Then, after that giving me some medicine (he gives me some medication)." (Informant 5)

"Aaaa... doctor told me to come for regular checking. For the next appointment, he also gave me the medical prescription and asked me not to miss out taking the medicine." (Informant 6)

\section{iv) Changing medications}

Other than that, the medical practitioner was also found out to be changing the medical prescriptions given to the patients in response to the patients' health condition. Informant 1 for example was unable to describe the medicine that he has to consume during his first few meetings with the doctor who were handling his case. The excerpt below further elicits the situation faced by Informant 1:

"Yeah, they prescribe me with....actually they changes my medication. So, at first I don't know what is my medication (my medication is)." (Informant 1) 


\section{v) Doctor's confusion}

In the in-depth interviews conducted, the researcher managed to derive the theme of 'doctor's confusion' based on the situation whereby the doctor was not able to make sense of the patient's complaint. The excerpts below explain the situation faced by Informant 1 and Informant 3:

"I don't think they fully understand... because I was in a disordered speech. I'm saying stuff not in order, than repeating a lot of stuff." (Informant 1)

"His speech indicated that he did not fully understand my situation. However, he just asked me to take the medication that will help to make me feel happy. That was not the answer I was looking for." (Informant 3)

\section{vi) Asking questions}

In a normal medical transaction, doctors will usually have the right to ask questions in order to analyse the true nature of the patient's health condition. Therefore, the informants involved in the in-depth interviews indicated that most of the time the doctors will ask them many questions which can help to direct them to the source of the health problem. The excerpts below explain the theme of 'asking questions' indicated in the in-depth interviews:

Researcher: Did he request you to repeat your complaint?

Informant 1: No. They keep on asking a lot of questions to direct my speech to an ordered way (make me speak in order).

"They do interaction with me as...how do you say? Go on better (getting better). As the thing progress, they kept asking more lah...” (Informant 2)

"Usually the doctor will listen to us first. Then he will keep on asking questions. He will make comparisons with our current condition with the previous one. Thus he will evaluate us, whether we do follow (whatever it is we will just follow) instructions and take medications" (Informant 6)

\section{vii) Provide materials to read}

During the treatment process, the medical practitioner had also come up with the initiative of assisting the patient in understanding the nature of their mental illness. Such initiative can be seen in the researcher's conversation with Informant 1 which is presented as follow:

"Yeah, at first I just accept it without any reasoning while later on I knew about schizophrenia. They gave me some stuff to read on." (Informant 1)

\section{viii) Background check}

Normally, before a consultation process begins in any medical transaction, the medical practitioners will tend to ask patients regarding to their personal background. The doctor will record information such as name, age, marital status, address and occupation in order to fill in the documentation required by the hospital or clinic attending the patients. The excerpts below explained the situation experienced by Informant 2 and Informant 6:

"They will ask me where I'm from, what are you doing and all that." (Informant 2)

"During our first meeting, I gave him all the details regarding to my personal background. Depending on what the doctor was asking. After that I told the doctor my background and the condition I'm having, and the doctor wrote them in a log book." (Informant 6) 


\section{ix) Show little understanding}

According to Wood [9], there are eight basic principles of interpersonal communication. The first principle listed is "we cannot not communicate". Communication does not only occur when we open our mouth and speak on something. Therefore, we cannot avoid ourselves from communicating with others, as people will always interpret what we say and what we do, as well as what we do not say and what we do not do [9]. Informant 2 mentioned that the doctor attending him has spoken in the fewest manner possible, indicating that the doctor has demonstrated little understanding in handling his health problem. The excerpt below explains the situation experienced by Informant 2:

Researcher: So, what did the doctor said when he heard about your complaint? What did the doctor reply when you say that you are having your problem? What did the doctor said? Did he understand?

Informant 2: He understand, but little.

\section{x) Changing doctors}

In a situation involving Informant 2, the medical practitioners treating him has been changing since his first appointment with the hospital. However, the hospital was unaware that Informant 2 was uncomfortable and having difficulties in explaining his condition all over again with different doctors. The excerpt below explains the situation experienced by Informant 2:

"Because my doctors sometimes changed... it depends on what the.... referred case (the case referred to the doctor)." (Informant 2)

\section{xi) Inconsistent explanation}

In the interview session conducted with Informant 2, the researcher managed to uncover the theme of 'inconsistent explanation' to indicate that the medical practitioner inability to deliver a good explanation regarding to the patient's health condition. Such indicator can be seen in the excerpt provided below:

Researcher: Did the doctor give a good explanation?

Informant 2: Sometimes yes, sometimes no.

\section{xii) Insensitive attitude}

In consulting the patient regarding to their health problems, the medical practitioners need to provide detailed explanation in order to gain the patient's trust. When it comes to dealing with our physical form, trust is one of the important rules that a doctor must gain from his patient. Thus, if the medical practitioner does not take the case seriously by hesitating on the patient's condition, the patient's health might be at stake. The excerpt below explains the situation experienced by Informant 3:

"The doctor at that time seems to be giving out normal views regarding to my condition. It seems like he is not taking my condition seriously. He does not ask questions to me, like other doctors usually did to their patients. " (Informant 3)

In any medical interactions, Rimon [8] described health communication as a process that can create partnership and participation based on the interactive exchange of information, ideas, techniques and also knowledge. However, such exchanges cannot occur if there were no two ways interaction, such as questioning and answering process occur in a health transaction. The excerpt below further elicits the situation described by Informant 3:

"The doctor at that time seems to be giving out normal views regarding to my condition. It seems like he is not taking my condition seriously. He does not ask questions to me, like other doctors usually did to their patients." (Informant 3) 
In a situation described by Informant 3, he was not happy with the explanation given by the medical practitioner who was attending him. The doctor was not actually answering to his questions during the consultation process, thus making it hard for him to understand the nature of his illness. The excerpts below further elicit the situation described by Informant 3:

"Yes, he didn't answer my questions just like any other detailed doctors, answering to all of the questions no matter what." (Informant 3)

"The doctor actually did not answer any of my questions. He just introduced me to the medications and asked me to consume all of them." (Informant 3)

\section{xiii) Conducting short session}

Another theme that can be derived from the in-depth interview with the informants is the 'short session' conducted by the medical practitioner as a respond to the patients' complaint. According to Thiedke [4] patients' satisfaction can be achieved if the doctor spends much more time to entertain the patient in the medical interaction. Therefore, the duration of the visit must meet the expectation brought up by the patients' curiosity in diagnosing and also treating his illness [3]. However, inadequate time spent by the medical practitioner can cause dissatisfaction, especially when most of the patients' curiosity was not provided with any explanations. The excerpt below explains the situation of Informant 3:

"Throughout my session with the doctor, it will only cost him not more than 20 minutes of his time." (Informant 3)

\section{xiv) No further explanation}

In certain cases, the medical practitioners provided less information regarding to the illness of the patient. Therefore, patients tend to be dissatisfied with the medical provider due to the lack of information provided to them [6]. The excerpts below further elicit the situation experienced by Informant 3, 4 and 6:

"The doctor only requires me to take the medication. However, he did not go further into telling me the condition of my illness. That's what I'm not satisfied of."

(Informant 3)

Researcher: So, are you saying that you are not given enough information regarding to your illness?

Informant 3: Exactly, I really didn't get any information that I wanted to!

Researcher: So did the doctor provide you with a good, I mean an in-depth explanation regarding to your health problem?

Informant 4: No, no, no. None of the doctors have ever done that. None of the doctors...

"Well, the explanation has not been given to me as to why I'm feeling (having) this problem. So there's nothing to say about this. But, what I can say is I've improved tremendously. I was no longer in the stage where I couldn't cope with myself. I have to rely on people to do things for me. But now I can you know (I can at least) at least do things by myself and that is I'm very glad of." (Informant 4)

"Ooo... The doctor, he hasn't told much. He will just have this small talk with me. He doesn't talk much because I think he doesn't want his patient to feel worry of their health condition." (Informant 6)

\section{xv) Not aware of patients' condition}

In some medical interactions, the doctor was unaware of the double condition experienced by his patient. Unfortunately, the decision to proceed with only one examined condition has caused the patient to be unsatisfied with the treatment that she received. The excerpt below explains the situation of Informant 4: 
"Yeah...If I can recall, the first time I was sent into the emergency department in GH (General Hospital). And the first encounter with the doctor was a, he did not know why was the reason behind why I was behaving strangely. My sister who accompanied me to see the doctor (my sister was the one who brought me to see the doctor). I explained to the doctor what the problems I was facing at home. So, then I came (when I faced) and faced the doctor I told him exactly what was the problem you know and he just gave me medication for it. Because I have two conditions, one is heart condition, and the other one is schizophrenia. But he just treated me for schizophrenia without knowing about my heart condition at the first place." (Informant 4)

\section{xvi) Blood samples and $x$-ray}

In a normal medical session, the medical practitioner will be conducting a check-up in order to analyse the patients" condition. Taking blood samples and also performing X-ray are a formality in any medical institutions. The excerpt below further explains the situation of Informant 4:

"I was warded, I think about two weeks. Yeah, in the hospital because they want to observe what was going on. So, during that time, I think they took blood samples if I'm not mistake. And then I have to go for x-ray and all that. So then I was discharged and given medication to take." (Informant 4)

\section{xvii) Asking patients' condition}

A medical practitioner will be assigned to consult the patients, attend the patients with the best treatment, performing operations and also investigating the medical cases reported to them [12]. Therefore, it is a formality for the medical practitioner to ask for the patients' information regarding to their health condition during the session. The excerpt provided below explains the situation of Informant 4:

"They never talked to me in the first place. You know, when I go and see the doctor, the doctor will ask me how are you (you are feeling) today. Then I have to explain to him what (are) the symptoms I had. Then he writes the medication down and that's it." (Informant 4)

\section{xviii) Writing in a file}

One of the tasks that have to be performed by a medical practitioner is writing down the details given by the patient for the purpose of proper documentation of the patients' progress. The doctor in-charge of the case must be notified by the patients. This is because any information shall be accountable in order to determine the right medical prescription and the treatment process that the patient will be receiving. The excerpt provided below explains the situation of Informant 4:

"Well it was normal to them because I remember the first doctor that I came to tell (me) about my problems. He just wrote down a lot of things in my file. And then a lot of times initially when I go and see a doctor, they write a lot of things. They keep on writing and then it's just medication, and you have to take your medication and that's it. There's no interaction as to why I'm facing this problem. There's no answer as to why I'm having this difficulty. There's no answer about what I'm supposed to do in the future. There's nothing, no clear guideline as to how interact with this problem." (Informant 4)

\section{xix) Refuse to listen to patients'opinion}

According to Stasso [1], the interrelationship between patient and the practitioner in the medical context need to be optimized in order for the medical system to function effectively and also efficiently. Thus, such relationship can be achieved by practicing effective communication during the early stage of the medical process. However, in the situation experienced by Informant 4, 
the medical practitioner attending her does not practice effective communication in the sense of neglecting the opinion given by the patient herself. The excerpt provided below further elicits the situation of Informant 4:

"Well, there was one stage where I was very unhappy with the doctor because no matter how I tried to explain to the doctor, the doctor was not satisfied with my explanation. So I can't remember exactly. I think it was many years ago la when I told the doctor that I had a heart condition and he refused to listen to my explanation. He kept on saying you do not have a heart condition. So I was very upset about that because it has been diagnosed with me that I've already had a heart condition, and yet you try to say that there's no. And I've also done ECG and all the things that show that I have a heart condition. But the doctor keeps on saying that I don't have a heart condition and everything is normal. So I'm very upset about that." (Informant 4)

\section{xx) Nonverbal expression}

Other than verbal expressions, nonverbal expression was also pointed out as one of the themes derived from the in-depth interview involving the researcher and Informant 4 . As mentioned by Informant 4, the doctor will listen to the patient and besides writing down the details, they will also node their head as a sign of following every single details expressed by the patient. The excerpt provided below further elicits the situation of Informant 4:

"Well, whenever I tell them about my problems, they will node their heads, write down prescription like I said earlier, write prescriptions and I go (and take my medication) for medication than that's it." (Informant 4)

\section{xxi) Checking on patient}

Medical check-up has long been a formality in any medical interactions. Doctors will tend to ask on the patient's condition and also providing them with the proper consultation on which medication that the patients will consume. The excerpts below further elicit the situation of Informant 5:

"I just go and see the doctor. Doctor was just look (looking) at me. Check on me (examining me)... then after that giving me some medicine.” (Informant 5)

"No. I was having some medical check-up. He just said that my cholesterol little bit high and so on. Nothing much on the issue. This is my private doctor. Normal checking la (having my routine check-up)." (Informant 5)

\section{xxii) Ask to come for regular check-up}

In the process of identifying the patients' illness, the doctor needs to keep in touch with the patient by asking them to come for regular checking. Follow up appointments can help both patient and the medical practitioners to identify the source of the disease and what kind of treatment process suitable in order for the disease to be cured. The gist of the in-depth interview conducted with Informant 5 and Informant 6 explain the situation:

"He asks me just to come to.... some is (are) 3 months regular checking. Now it's every six months. So every six months I have to go and see the doctor." (Informant 5)

"Aaaaa... Doctor asked me to come for the next appointment. Then he will give me the next medication and make sure that I will never missing taking the pills. " (Informant 6) 


\section{CONCLUSION}

In the situation involving medical practitioner's reaction towards the patient's complaint, the researcher has come out with a conclusion indicating that the medical practitioners involved in treating the informants were not responsive enough to the patients' complaint. In the in-depth interviews involving six informants, the researcher has found out that most of the themes derived were indicating negative reactions from the medical practitioners. Examples of negative reactions are minimum reply, short session, not providing enough information and refusing to listen to patients' opinion. In the process of understanding the patient's situation, the medical practitioners need to understand the importance of listening. According to Harter et al [11] listening can be linked with successful communication within highly technical fields such as the field of medicine whereby the doctor who have improvised their listening skills are less associated with malpractice claims from the patients.

\section{IMPLICATIONS}

There are a few implications that can be derived from this research. First and foremost, this research can help the Ministry of Health to act as the policy maker in coming out with a guideline that can help to educate medical practitioners in providing medical services to the citizens of Malaysia. This is important in order to ensure that people will change their perceptions of how poor government hospitals are in terms of customer care and also services provided. If the medical practitioners are still practicing poor communication skills, they jeopardize not only their credibility, but also the credibility of the medical system in the country. Other than that, this research can also help in assisting the medical practitioners in the process of gaining an in-depth understanding of the patients' situation. This is important to ensure that the medical interaction occurs between both parties can provide the patients with the most optimum outcome. Such optimum outcome can be in form of providing the best treatment and also medication in such an efficient period throughout the medical process. Furthermore, this research can also contribute towards the body of knowledge by assisting educators or lecturers in the medical field to come out with significant courses or subjects specifically for medical undergraduates. According to Braham et al [7], medical students are expected to be competent in the following areas of communication:

1) Listening, to patients, relatives / carers / partners, and other healthcare professionals.

2) Explaining, and providing patients and others with adequate information.

3) Mediating and negotiating with patients, carers and colleagues.

Therefore, communication based courses such as Introduction to Communication Theory, Persuasion and Negotiation and also Conflict Management can be implemented in any field of medical based studies in order to help the medical undergraduates to be well prepared before entering the actual working environment.

\section{RECOMMENDATION}

There are a few recommendations that can be implemented in order to improvise future researches. First and foremost, a similar study can be conducted in by implementing the quantitative method in order to get more views from larger amount of respondents, regardless of the illness or disease that the respondents' are or were experiencing. Questionnaires can be formulated in order to help the quantitative researcher to understand the nature of interpersonal communication problems involving patients and the medical practitioners. Secondly, the researcher has also come out with the recommendation of utilizing the same structure of research but with different sets of informants. In this research, the informants chosen to undergo the in-depth interview were selected on the basis of experiencing mental illness. Thus, a different set of informants such as heart disease or orthopaedics patients can be used to further extent the scope of the research. Such improvisation can help future researcher to determine the actual source of problems that occur in the medical interactions involving patients and the medical practitioners, thus deducting the sense of biasness the current research that have been done initially. 


\section{References}

[1] A.K. Stasso, "Factors affecting the quality of practitioner-patient communication (and Care): implications for medical education," Ph.D. dissertation, Ed, uwindsor, Windsor, Ontario, 2011.

[2] B. Bonder, R. M. Perloff, E. B. Ray, G. B. Ray and L. A. Siminoff, "Doctor-patient communication, cultural competence, and minority health: theoretical and empirical perspectives," American Behavioural Scientists, vol. 49, pp. 835, 2006.

[3] C. B. Domingo, "Doctor-Patient communication in the medical interaction: context, implications, and practices," Ph.D. dissertation, UTSPH, Houston, Texas, 2010.

[4] C. C. Thiedke, "What do we really know about patient satisfaction?" Family Practice Management, vol.14 (1), pp. 33-36, 2000.

[5] C. K. Riessman, Narrative analysis. Newbury Park, CA: SAGE, 1993.

[6] I. Blix, P. G. Farup, S. Forre, G. Johnsen, R. Johannessen, O. Lange and H. Petersen, "What causes treatment failure-the patient, primary care, secondary care or inadequate interaction in the health services?” BMC Health Services Research, vol. 1, pp. 1472-6963, 2011.

[7] J. Braham, C. Elston and T. Shepherd (2010). Listening and interpersonal skills review [Online]. Available: http://www.learnhigher.ac.uk//

[8] J. G. I. Rimon, "Behaviour change communication in Public Health," in United Nation Roundtable on Development Communication, Managua, Nicaragua, 2001.

[9] J. T. Wood, Interpersonal communication: everyday encounters. California: Thomson Wadsworth, 2007.

[10]L. D. Brown, B. de Negri, O. Hernandez, D. Roter and J. Rosenbaum (1991). Improving Interpersonal communication between health care providers and clients [Online]. Available: http://www.urc-chs.com/

[11]L. Harter, P. Nelson, P. Pearson and S. Titsworth, Human communication. New York: McGraw-Hill, 2008.

[12] Queensland Health (2009). Medical practitioner: a career in health fact sheet series [Online]. Available: //www.health.qld.gov

[13]R. E. Boyatzis, Transforming qualitative information: Thematic analysis and code development. Thousand Oaks, CA: SAGE, 1998.

[14] S. B. Meriam, Qualitative research and case study applications in education. San Francisco: Jossey-Bass Publishers, 1998.

[15] V. Braun and V. Clarke, "Using thematic analysis in psychology," Qualitative Research in Psychology, vol. 3 (2), pp. 77-101, 2006. 